\title{
Plasma Surface Functionalization of Biaxially Oriented Polypropylene Films with Trimethyl Borate
}

\author{
Nursel Dilsiz ${ }^{1^{*}}$, Hande Yavuz ${ }^{1}$, Süleyman Çörekçi ${ }^{2}$, Mehmet Çakmak ${ }^{3}$ \\ ${ }^{1}$ Department of Chemical Engineering, Gazi University, Ankara, Türkiye \\ ${ }^{2}$ Department of Physics, Kırklareli University, Kırklareli, Turkey \\ ${ }^{3}$ Department of Physics, Gazi University, Ankara, Türkiye \\ E-mail:"ndilsiz@gazi.edu.tr \\ Received May 1, 2011; revised June 19, 2011; accepted June 18, 2011
}

\begin{abstract}
The radiofrequency plasma $(13.56 \mathrm{MHz})$ was employed to polymerize trimethyl borate (TMB) monomer/ $\mathrm{N}_{2}$ gas mixture on the surface of biaxially oriented polypropylene (BOPP) films. Plasma polymer coated polypropylene films were examined by flame retardancy test (limiting oxygen index, LOI). The highest LOI value calculated for the untreated BOPP sample was $18.4\left(\mathrm{v} / \mathrm{v} \mathrm{O}_{2} \%\right)$ and $24.2\left(\mathrm{v} / \mathrm{v} \mathrm{O}_{2} \%\right)$ for the $55 \mathrm{~W} 30$ minutes treated sample. The plasma polymers were characterized by FTIR spectroscopy and AFM. According to the FTIR results, the $-\mathrm{OH}, \mathrm{B}-\mathrm{CH}_{3}, \mathrm{~B}-\mathrm{O}$, and $\mathrm{BH}_{2}$ functional groups were detected. It was found that the highest surface roughness belonged to $40 \mathrm{~W} 30 \mathrm{~min}$ treated BOPP sample which was calculated as 9.78 $\mathrm{nm}(10 \mu \mathrm{m} \times 10 \mu \mathrm{m})$. Moreover, the wettability of the modified BOPP film surfaces was characterized via contact angle measurements. The water contact angle values have decreased from $109.6^{\circ}$ to the lowest value of $68.2^{\circ}$ after the plasma treatment. The results showed that $\mathrm{TMB} / \mathrm{N}_{2}$ plasma modification could be used as an alternative method for the enhancement of flame retardancy and hydrophilicity of BOPP film.
\end{abstract}

Keywords: Polypropylene Film, Trimethyl Borate, Plasma Treatment, Flame Retardancy, Hydrophilicity

\section{Introduction}

It is well known that the thermal and the mechanical properties of the polyolefins vary with their type and the degree of their crystallinity. Some of these polymers such as low modulus and low tenacity type polypropylene exhibit low thermal resistance and low tensile strength. In order to enhance their thermal resistivity and mechanical strength, surface modification or layer deposition in micrometer or nanometer scale may be employed.

Among all other modification processes plasma modification draws great attention over the past years due to the discovery of its various advantages comparing to conventional methods [1]. Cold plasma process, which is an environmentally friendly and safe method, allows the surface of any polymer to be changed to achieve the desired functionality while retaining the bulk properties of material. Due to the fragmentation of organic compounds one may not always obtain the expected polymer formations by plasma polymerization [2]. In other words, organic vapor polymerization under the influence of plasma is quite complex and can not be specifically des- cribed by general cases. In plasma treatments, a wide variety of monomers can be used for various applications. According to the applied plasma conditions and selected substrate types, desired functional film layer formations can be obtained in a very short time. For example, monomers such as oxygen based ones can lead to the formation of carboxylic acids, ketones and esters where, nitrogen based monomers show high level of nitrogen incurporation into the deposited polymer layer [3]. Typically, these plasma polymers have high degree of branching and crosslinking in comparing to conventional polymeric structures [2]. Jama et al. [4-6] reported first promising results for improvement of fire behavior of polymer surface by plasma modification with organosiloxanes. Schartel et al. [7] described the surface controlled fire retardancy of polyamide films using plasma polymerization of hexamethyldisiloxane. According to the authors, plasma polymer growth on the suitable substrate surfaces can be optimized by controlled plasma process parameters and the resultant chemical structure of the plasma coated layer could be sufficient to prevent the entire combustion of material. Besides, many types of flame retardants 
which are available in consumer products are mainly composed of phosphorus, antimony, aluminum, chlorides, bromides [8-10] and boron-containing compounds. During the thermal degradation of polymers, borates leads to the formation of impenetrable glass coatings on the surface of materials, therefore they can be classified in the effective flame retardants [11].

In this current research, BOPP films were modified in $\mathrm{TMB} / \mathrm{N}_{2}$ gas mixture in order to improve the flame retardancy of polymer films. To describe and to measure the properties of BOPP films response to heat and flame, Limiting Oxygen Index (LOI) method was evaluated. Fourier Transform Infrared Spectroscopy (FTIR) was used in the determination of the chemical structure of functionalized surface. Atomic Force Microscopy (AFM) and wettability measurements were carried out to characterize the surface properties of BOPP films. The results showed that $\mathrm{TMB} / \mathrm{N}_{2}$ plasma modification could be used as an alternative method for the enhancement of flame retardancy and hydrophilicity of BOPP film.

\section{Experimental}

\subsection{Materials}

Biaxially oriented polypropylene films (BOPP, thickness: $40 \mu \mathrm{m}$ ), which were supplied by Super Film A.S. (Gaziantep, Turkey), were used as received. Trimethyl borate (TMB), $\mathrm{B}\left(\mathrm{OCH}_{3}\right)_{3}$ was supplied by Fluka (Germany). The code of materials used in this study is given in the Table 1.

\subsection{Surface Modification of BOPP Films}

The radio frequency (RF) plasma was generated by Diener Electronic Pico UHP system (Germany) at 13.56 $\mathrm{MHz}$ with an electrical power ranging between $0 \mathrm{~W}$ and $100 \mathrm{~W}$. The applied discharge power of $30 \mathrm{~W}, 40 \mathrm{~W}, 55$ $\mathrm{W}$, and $80 \mathrm{~W}$ was chosen. The impedance match between the reactor chamber and the radiofrequency generator was optimized by the matching network, which provided power loses at the minimum. The dimension of a cylindrical shaped quartz plasma reactor was $130 \mathrm{~mm}$ (diameter) $\times 300 \mathrm{~mm}$ (length) and two copper electrodes were located on the reactor externally. A combination of cold trap and vacuum pump was used to maintain the pressure range in the reactor between 0.1 mbar and 1 mbar. In the absence of the TMB/ $\mathrm{N}_{2}$, the pressure of the reactor was decreased to about 0.1 mbar. The BOPP film and $\mathrm{NaCl}$ crystal were used as the substrates onto which the plasma polymer films were deposited and were placed in the reactor and treated simultaneously with the same plasma conditions. The plasma polymer coated on the $\mathrm{NaCl}$ crystals were used to determine the FTIR spectra of the
Table 1. Code of materials used in this study.

\begin{tabular}{lc}
\hline \multicolumn{1}{c}{ Specimen code } & \multicolumn{1}{c}{ Description } \\
\hline BOPP & $\begin{array}{c}\text { Untreated biaxially oriented polypropylene } \\
\text { film }\end{array}$ \\
BOPP-N 2 TMB30W30M & $\begin{array}{c}\text { At 30 W and for 30 min nitrogen gas and } \\
\text { trimethyl borate plasma treated BOPP film }\end{array}$ \\
BOPP-N 2 TMB40W30M & $\begin{array}{c}\text { At 40 W and for 30 min nitrogen gas and } \\
\text { trimethyl borate plasma treated BOPP film }\end{array}$ \\
BOPP-N 2 TMB55W30M & $\begin{array}{c}\text { At 55 W and for 30 min nitrogen gas and } \\
\text { trimethyl borate plasma treated BOPP film }\end{array}$ \\
BOPP-N 2 TMB80W30M & $\begin{array}{c}\text { At } 80 \mathrm{~W} \text { and for 30 min nitrogen gas and } \\
\text { trimethyl borate plasma treated BOPP film }\end{array}$
\end{tabular}

$\mathrm{NaCl}$

Untreated pure $\mathrm{NaCl}$ crystal

NaCl-N 2 TMB30W30M

At $30 \mathrm{~W}$ and for $30 \mathrm{~min}$ nitrogen gas and trimethyl borate plasma treated $\mathrm{NaCl}$ crystal

$\mathrm{NaCl}-\mathrm{N}_{2}$ TMB40W30M

At $40 \mathrm{~W}$ and for 30 min nitrogen gas and trimethyl borate plasma treated $\mathrm{NaCl}$ crystal

NaCl-N 2 TMB55W30M

At $55 \mathrm{~W}$ and for $30 \mathrm{~min}$ nitrogen gas and trimethyl borate plasma treated $\mathrm{NaCl}$ crystal

NaCl-N 2 TMB80W30M

At $80 \mathrm{~W}$ and for $30 \mathrm{~min}$ nitrogen gas and trimethyl borate plasma treated $\mathrm{NaCl}$ crystal

polymer film. The substrates were pretreated in the plasma chamber with argon gas before each plasma operation to clean and to improve the adhesion of the flame retardant coating. When the $\mathrm{TMB} / \mathrm{N}_{2}$ mixture was fed into the reactor by a needle valve, the pressure was adjusted to 0.26 mbar - 0.30 mbar and was kept at that level during the plasma operation. Polymerization were carried out for $\mathrm{TMB} / \mathrm{N}_{2}$ under different discharge power and plasma exposure time was kept constant at 30 minutes. Additionally, the effluents from the reactor in which plasma polymerization took place were discharged through a piping system. After the completion of treatment, argon was fed into the reactor for $15 \mathrm{~min}$ to deactivate free radicals. For a given conditions, all experiments were carried out as triplicate.

\subsection{Characterization of Plasma Surface Modified BOPP Films}

FTIR spectra of the plasma polymers deposited on $\mathrm{NaCl}$ were recorded by using Jasco 480 Plus FTIR spectrometer having an $8 \mathrm{~cm}^{-1}$ resolution. FTIR spectroscopy was 
used to determine the functional groups present in a molecule. The infrared region was taken from $4000 \mathrm{~cm}^{-1}$ to $400 \mathrm{~cm}^{-1}$ wavenumbers where the most vibrations mainly occur.

In order to determine the effect of the deposited film layer on the surface topography, the BOPP samples were examined by atomic force microscopy (AFM). Surface topography of $\mathrm{TMB} / \mathrm{N}_{2}$ plasma modified BOPP film was investigated by AFM operated in tapping mode on an Omicron VT STM/AFM Instrument. The main objective of the collection of AFM images is to measure the atomic level forces between the sample surface and the probe. Acquiring images over a small area is possible with the small probe-specimen separation, thus, in this work scanning ranges were adjusted to $10 \mu \mathrm{m} \times 10 \mu \mathrm{m}$. The images were collected while the tip was operated at Tapping Mode. Roughness (RMS) was determined as a mean from five AFM scans over the same area.

Fire response of plasma modified BOPP films were studied according to the LOI test method under controlled laboratory conditions described in ASTM D 2863-00 standard [13]. Dynisco LOI polymer test equipment was used to determine the flammability of the films according to the ASTM D 2863 standard. According to the test method, flexible films (e.g. BOPP films) should be supported vertically in the center of a heat resistant transparent chimney and tested in accordance with the test method B. At least fifteen specimens were prepared in order to maintain LOI and fire response unmodified and each plasma modified sample. In order to assess fire response of individual test specimens, period and extent of burning were considered. Dixon's "Up-and-Down" method, which is described in ASTM D 2863-00 standard, was used to calculate the LOI of each series of specimens.

The wettability tests for the BOPP films were perfor- med on Krüss100 DSA equipped with a fast CCD camera. Sessile drop type was selected for the static contact angle setup, and distilled water was used for the each contact angle measurement. Five separate $\mathrm{TMB} / \mathrm{N}_{2}$ plasma modified films were measured to get an average value.

\section{Results and Discussion}

\subsection{FTIR Spectroscopy}

The chemical structure of plasma modified BOPP film, which was treated under $\mathrm{N}_{2}$ gas and TMB vapor, indicated that at the surface mainly boron based functional groups were included. Since the methylene deformations mainly occur between $1500 \mathrm{~cm}^{-1}$ and $1300 \mathrm{~cm}^{-1}$ wave numbers, plasma polymer coated $\mathrm{NaCl}$ crystals were used to help the identification of $\mathrm{B}-\mathrm{CH}_{3}, \mathrm{~B}-\mathrm{O}, \mathrm{BH}_{2}$ functional groups which consistently produce absorption bands between $1460 \mathrm{~cm}^{-1}$ $1405 \mathrm{~cm}^{-1}, 1350 \mathrm{~cm}^{-1}-1310 \mathrm{~cm}^{-1}$ and $1205 \mathrm{~cm}^{-1}-1140$ $\mathrm{cm}^{-1}$, respectively. In order to relate plasma power effect with constant plasma exposure time (at $30 \mathrm{~min}$ ), the FTIR spectra were collected as represented in Figure 1. It can be seen that almost all of the plasma polymers obtained from different $(30 \mathrm{~W}, 40 \mathrm{~W}, 55 \mathrm{~W}$ and $80 \mathrm{~W})$ discharge power gave similar characteristic peaks, indicating similar functional groups in the plasma polymers. In general the relative intensities of these peaks have varied with increasing discharge power. One of the major peaks observed for all plasma polymers was obtained at $3450 \mathrm{~cm}^{-1}-3100 \mathrm{~cm}^{-1}$, which is mostly due to O-H stretching band. The peak at $1460 \mathrm{~cm}^{-1}-1405 \mathrm{~cm}^{-1}$ can be assigned to $\mathrm{B}_{-} \mathrm{CH}_{3}$ symmetrical deformation and absorption at $1205 \mathrm{~cm}^{-1}$ $1140 \mathrm{~cm}^{-1}$ may be assigned to $\mathrm{BH}_{2}$ in-plane deformation [14]. Aditionally, the formation of B-O stretching band was observed at $1350 \mathrm{~cm}^{-1}-1310 \mathrm{~cm}^{-1}$ at $30 \mathrm{~W}$ discharge power.

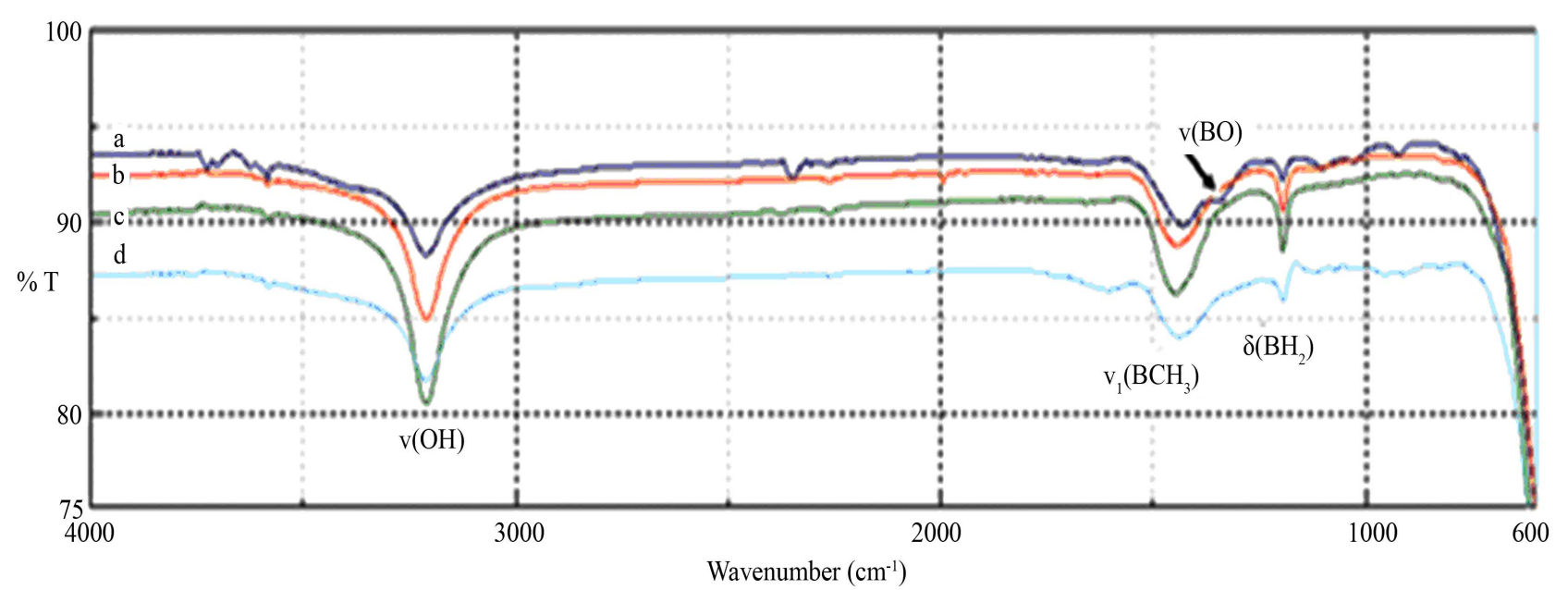

Figure 1. FTIR spectra of plasma polymers at exact plasma exposure time a) $30 \mathrm{~W}$, b) $40 \mathrm{~W}$, c) $55 \mathrm{~W}$, d) $80 \mathrm{~W}$. 
The formation of new groups in the TMB plasma polymer $\left(\mathrm{BH}_{2}, \mathrm{~B}-\mathrm{CH}_{3}\right.$, etc. $)$ is mainly caused by the fragmentation of monomers under plasma conditions. Due to fragmentation of organic compounds in plasma the polymer formed is not always what one would expect from the chemical structure of the monomer [15]. When the discharge power was increased to $55 \mathrm{~W}$, the intensities of the peaks has increased slightly. The absorption intensities for all plasma polymers seemed to increase first upon increasing the discharge power up to $55 \mathrm{~W}$. When the discharge power was raised to $80 \mathrm{~W}$ the intensities of all the peaks have decreased. This result can be explained by the fact that by increasing discharge power a growing portion of the modified polymer is ablated [16] and thinner layer of modified polymer is available for subsequent FTIR measurement. It can be concluded that the decrease in the peak intensites may be due to increased decomposition of the deposited polymers with increasing power.

\subsection{Limiting Oxygen Index (LOI)}

Results of oxygen index test are given in Table 2. The results demonstrate that $\mathrm{TMB} / \mathrm{N}_{2}$ plasma polymers modified BOPP film have higher LOI value than the untreated BOPP film. From Table 2 it can be seen that when plasma power increases to $30 \mathrm{~W}$, LOI value $\mathrm{TMB} / \mathrm{N}_{2}$ plasma treated BOPP film increases from 18.4 (untreated BOPP) to $23.6\left(\% \mathrm{O}_{2}, \mathrm{v} / \mathrm{v}\right)$. When the plasma power increases to $55 \mathrm{~W}$, the maximum LOI value obtained was $24.2\left(\% \mathrm{O}_{2}, \mathrm{v} / \mathrm{v}\right)$. The LOI difference between untreated and plasma modified films was calculated as approximately $30 \%$. This trend could be related to the deposition of B-O functional groups rather than the deposition of B-C and/or B-H functional groups, which can be formed in the cold plasma environment, on the surface of the BOPP films. This conclusion was also supported by FTIR spectra given in Figure 1.

\subsection{Atomic Force Microscopy}

The effect of plasma discharge power on the surface morphology of $\mathrm{TMB} / \mathrm{N}_{2}$ modified BOPP can be seen

Table 2. LOI data for plasma treated BOPP film.

\begin{tabular}{cc}
\hline Specimen code & LOI $\left(\mathbf{O}_{2} \%, \mathbf{v} / \mathbf{v}\right)$ \\
\hline Untreated BOPP & $18.4 \pm 0.20$ \\
BOPP-N 2 TMB30W30M & $23.6 \pm 0.18$ \\
BOPP-N 2 TMB40W30M & $22.5 \pm 0.16$ \\
BOPP-N 2 TMB55W30M & $24.2 \pm 0.27$ \\
BOPP-N 2 TMB80W30M & $22.4 \pm 0.21$ \\
\hline
\end{tabular}

from AFM images shown in Figure 2. As seen from the images, surface morphologies of the treated samples slightly changed compared to the untreated one.

Roughness was determined as a mean from five AFM scans over the same area and its dependence on discharge power is given in Table 3. As is shown in Figure $\mathbf{2}$, the effects of different power on surface morphologies of BOPP film were characterized by AFM. For the untreated BOPP film, the surface roughness was $5.64 \mathrm{~nm}$. However, after $40 \mathrm{~W} \mathrm{TMB} / \mathrm{N}_{2}$ plasma treated for $30 \mathrm{~min}$, the fiber surface roughness increased to $9.78 \mathrm{~nm}$. It was found that the untreated BOPP film had a smooth surface (Figure 2(a)). It can be found that BOPP films were notably roughened by the plasma power. The surface roughness of plasma polymer modified BOPP films enhanced with the plasma power up to $40 \mathrm{~W}$ then the surface rougness slightly decrease with increasing the plasma treatment power. These results indicate that BOPP film were notably roughened by the $\mathrm{TMB} / \mathrm{N}_{2}$ plasma treatment.

\subsection{Contact Angle}

Under various discharge conditions, it is found that the chemical structure of the top BOPP film layer was changed significantly. The relation between the treatment conditions and contact angle values can be followed in Table 4. It is known that plasma polymer deposition

Table 3. Surface roughness of untreated and plasma polymerized BOPP film.

\begin{tabular}{cc}
\hline Sample code & $\begin{array}{c}\text { Surface roughness (nm) } \\
10 \mu \mathrm{m} \times 10 \mu \mathrm{m}\end{array}$ \\
\hline BOPP & $5.64 \pm 0.83$ \\
BOPP-N 2 TMB30W30M & $7.27 \pm 0.72$ \\
BOPP-N 2 TMB40W30M & $9.78 \pm 1.25$ \\
BOPP-N 2 TMB55W30M & $7.85 \pm 0.52$ \\
BOPP- $\mathrm{N}_{2}$ TMB80W30M & $6.22 \pm 0.48$ \\
\hline
\end{tabular}

Table 4. Contact angle values of untreated and plasma polymerized BOPP film.

\begin{tabular}{cc}
\hline Specimen code & Contact Angle $\left(^{\circ}\right)$ \\
\hline Untreated BOPP & $109.6 \pm 0.25$ \\
BOPP-N 2 TMB30W30M & $73.6 \pm 2.65$ \\
BOPP-N 2 TMB40W30M & $68.2 \pm 1.58$ \\
BOPP-N 2 TMB55W30M & $88.6 \pm 5.00$ \\
BOPP- ${ }_{2}$ TMB80W30M & $83.3 \pm 0.72$ \\
\hline
\end{tabular}



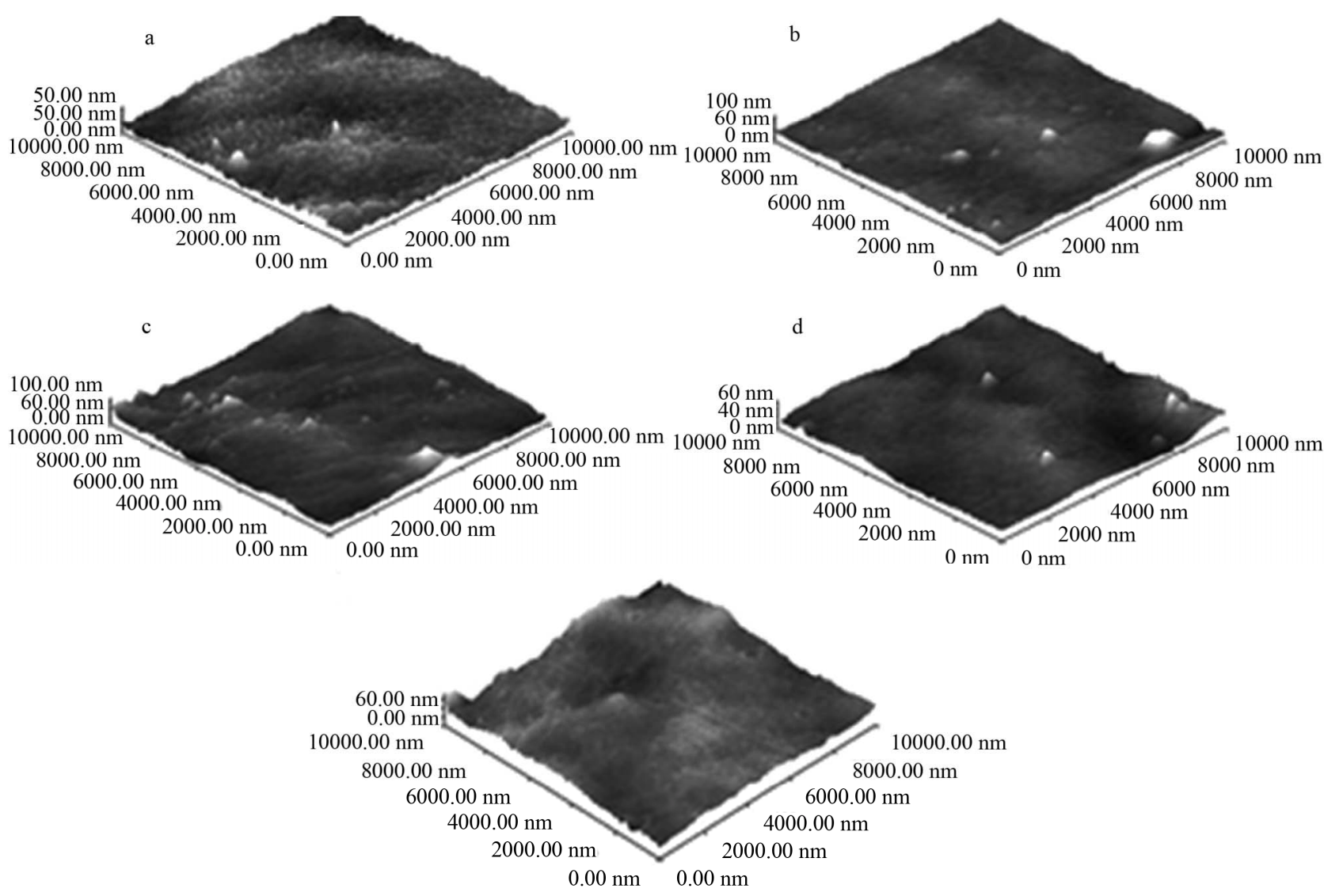

Figure 2. AFM images of a) Untreated BOPP film; b) BOPP- $\mathrm{N}_{2} \mathrm{TMB30W30M}$; c) BOPP- $\mathrm{N}_{2} \mathrm{TMB} 40 \mathrm{W30M}$; d) BOPP-N TMB55W30M; e) BOPP-N 2 TMB80W30M (10 $\mu \mathrm{m} \times 10 \mu \mathrm{m})$.

depends strongly on the nature of monomer type and discharge power. TMB $/ \mathrm{N}_{2}$ plasma led to the formation of polar groups (e.g. B-O, -OH) on the surface and caused the removal of some $\mathrm{C}-\mathrm{H}$ groups from the surface of BOPP film. So that, wettability of surface was increased, samples became more hydrophilic comparing to the original value $\left(108.3^{\circ}\right)$. While the highest contact angle was obtained at $55 \mathrm{~W}\left(88.6^{\circ}\right)$, the lowest one was obtained at $40 \mathrm{~W}\left(68.1^{\circ}\right)$. This can be attributed to the introduction of hydrophilic groups $(-\mathrm{OH})$ on the polymer surface which was seen on the FTIR spectra. All these results are quite interesting from the point of view of seeing no linear trend between the discharge power and contact angle. The differences among these values can be attributed to the change in distribution of polymer deposition due to the applied conditions. There seems to be no obvious correlation between surface roughness and discharge power. It can be seen that AFM images of $\mathrm{TMB} / \mathrm{N}_{2}$ plasma polymers and their structure have changed considerably upon increasing discharge power. These results follow the same tendency as reported by Svorick et al. [16] It is known that the value of the con- tact angle is mostly affected by the chemical structure and morphology of the polymer surface layer [17]. Various reactions that takes place during plasma polymerization include excitation, ionization, homolitic bond splitting, molecular fragmentation etc. For a low level of energy input, the extent of ionization is low and ionmolecule reactions dominate polymer formation resulting in deposition rate increase with power [18]. Above certain levels of energy, there is greater loss of functional groups from the monomer resulting in compe- titive polymerization and ablation [19].

\section{Conclusions}

We have focused on the plasma modification of BOPP films in the presence of $\mathrm{TMB} / \mathrm{N}_{2}$ in order to improve their tolerance to flame. Thus, in this work biaxially oriented polypropylene films have been examined mainly by means of their LOI values. It has been stated that the LOI values can be optimized by adjusting the discharge power and time. When the treatment time kept constant at 30 minutes, and the plasma power was adjusted to 55 
W, LOI of BOPP films obtained have increased from 18.4 to 24.2 . It can be seen that the plasma modified BOPP films have gained resistance to flame comparing to unmodified samples. Besides, the effects of plasma polymer deposition on the surface of BOPP film samples were studied from the AFM and FTIR results. These results have showed that boron-based functional layer deposition can be applied to enhance the flame retardancy of BOPP films.

\section{Acknowledgements}

This work was supported by National Boron Research Institute (BOREN) contact grant number BOREN-2006Ç-02 and The State Planning Organization (DPT) contact grant number $2001 \mathrm{~K}-120590$.

\section{References}

[1] N. Inagaki, "Plasma Surface Modification and Plasma Polymerization," Technomic Publication Co., Lancaster, 1996.

[2] N. Dilsiz and G. Akovali, "Plasma Polymerization of Selected Organic Compounds," Polymer, Vol. 37, No. 2, 1996, pp. 333-342. doi:10.1016/0032-3861(96)81107-4

[3] M. C. Porter, "Handbook of Industrial Membrane Technology," Noyes Publications, USA, 1990.

[4] S. Bourbigot, C. Jama, M. Le Bras, R. Delobel, O. Dessaux and P. Goudmand, "New Approach to Flame Retardancy Using Plasma Assisted Surface Polymerisation Techniques," Polymer Degradation and Stability, Vol. 66, No. 1, 1999, pp. 153-155. doi:10.1016/S0141-3910(99)00059-2

[5] C. Jama, A. Quede, P. Goudmand, O. Dessaux, M. Le Bras, R. Delobel, S. Bourbigot, J. W. Gilman and T. Kashiwagi, "Fire and Polymer Materials and Solutions for Hazard Prevention," G. L. Nelson, C. A. Wilkie, Eds., ACS Publication, ACS Symp Ser, Washington D. C., 2001, pp. 797-200.

[6] C. Jama, A. Quede, H. Sadiki, O. Dessaux, P. Goudmand, R. Delobel and M. Le Bras, "Recent Advances in Flame Retardancy of Polymeric Materials," M. Lewin, Ed., Business Communications Co., Norwalk, 2001, pp. 127-136.

[7] B. Schartel, G. Kühn, R. Mix and J. Friedrich, "Surface Controlled Fire Retardancy of Polymers Using Plasma
Polymerisation," Macromolecular Materials and Engineering, Vol. 287, No. 9, 2002, pp. 579-582. doi:10.1002/1439-2054(20020901)287:9<579::AID-MA ME579>3.0.CO;2-6

[8] J. Troitzsch, "International Plastics Flammability Handbook," Hanser Publications, New York, 1990.

[9] M. Sain, S. H. Park, F. Suhara and S. Law, "Flame Retardant and Mechanical Properties of Natural Fibre-PP Composites Containing Magnesium Hydroxide," Polymer Degradation and Stability, Vol. 83, No. 2, 2004, pp. 363-367. doi:10.1016/S0141-3910(03)00280-5

[10] S. Zhu and W. Shi, "Thermal Degradation of a New Flame Retardant Phosphate Methacrylate Polymer," Polymer Degradation and Stability, Vol. 80, No. 2, 2003, pp. 217-222. doi:10.1016/S0141-3910(02)00401-9

[11] C. Martin, J. C. Ronda and V. Cadiz, "Boron-Containing Novolac Resins as Flame Retardant Materials," Polymer Degradation and Stability, Vol. 91, No. 4, 2006, pp. 747-754. doi:10.1016/i.polymdegradstab.2005.05.025

[12] H. Yasuda and C. E. Lamaze, J. Appl. Poly. Sci, Vol. 14, 1971, p. 227.

[13] American Society for Testing and Materials, "D2863-00 Standart Test Method for Measuring the Minimum Oxygen Concentration to Support Candle-like Combustion of Plastics (Oxygen Index)," ASTM International, 2000, pp. 452-464.

[14] J. G. Grasselli, "CRC Atlas of Spectral Data and Physical Constants for Organic Compounds," 1973.

[15] H. Yasuda, M. Shen and A. T. Bell, eds., Plasma Polymerization, USA, 1978.

[16] V. Svorcik, V. Kotal, P. Slepicka, O. Blahova, M. Spirkova, P. Sajdl and V. Hnatowicz, Nucl. Instr. and Meth. in Phys. Res B, Vol. 244, 2006, pp. 365-372.

[17] K. Rockova, V. Svorcik, L. Bacakova, B. Dvorankova and V. Hnatowicz, "Bio-Compatibility of İon Beammodified and RGD-Grafted Polyethylene," Nuclear Instruments and Methods in Physics Research Section B, 2004, Vol. 225, No. 3, pp. 275-282. doi:10.1016/j.nimb.2004.05.004

[18] H. Yasuda, "Plasma Polymerization," Academic Press Inc., New York, 1985.

[19] L. O'Toole and R. D. Short, "An Investigation of the Mechanisms of Plasma Polymerisationof Allyl Alcohol," Journal of the Chemical Society, Faraday Transactions, Vol. 93, 1997, pp. 1141-1145. doi:10.1039/a607397b 